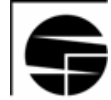

IIASA

\title{
Doing More with Less Improving the Environment through Green Engineering
}

\section{Arnulf Grubler}

RP-06-005

April 2006

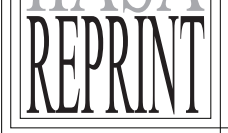





\section{Doing More with Less Improving the Environment through Green Engineering}

Arnulf Grubler

International Institute for Applied Systems Analysis, Laxenburg, Austria

RP-06-005

April 2006

Reprinted from Environment 48(2), pp. 22-37, March 2006.

International Institute for Applied Systems Analysis - Schlossplatz 1 - A-2361 Laxenburg • Austria Tel: (+43 2236) 807 • Fax: (+43 2236) 71313 •E-mail: publications@iiasa.ac.at•Web: www.iiasa.ac.at 
IIASA Reprints make research conducted at the International Institute for Applied Systems Analysis more accessible to a wider audience. They reprint independently reviewed articles that have been previously published in journals. Views or opinions expressed herein do not necessarily represent those of the Institute, its National Member Organizations, or other organizations supporting the work.

Reprinted with permission from Environment 48(2), pp. 22-37, March 2006.

Copyright () Heldref Publications, March 2006.

http://www.heldref.org/env.php

All rights reserved. No part of this publication may be reproduced or transmitted in any form or by any means, electronic or mechanical, including photocopy, recording, or any information storage or retrieval system, without permission in writing from the copyright holder. 


\section{Doing \\ with \\ with Le

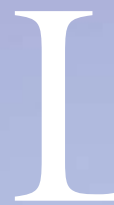 \\ ing

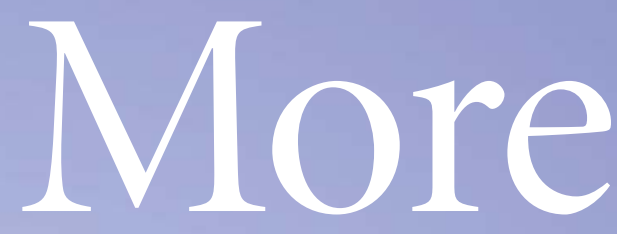 \\ Improving the Environment \\ through Green Engineering}

\section{by Arnulf Grubler}

Any effort to get at the root causes of long-term environmental problems-identifying them and crafting strategies to address them-must do so with a thorough understanding of the many facets of productivity growth: that is, how people do more with less. Most human endeavors have a long-standing interest in improving productivity, and while the variables differ between fields, the basic question can be boiled down to the economist's perspective: that productivity measures the inputs required per unit of output and that productivity drives the economy. Economists are interested in such productivity measures as the amount of labor (typically measured in personhours) needed for the manufacturing of an automobile or an aircraft. In agriculture, one of the key inputs is farmland, and the associated productivity measure is crop yield-the amount of food produced per unit land area. Engineers use a range of productivity measures to benchmark different processes with respect to key inputs. For example, an engineer needs to consider the amount of energy required to produce a ton of steel or cement.

More recently, environmentalists have also taken an interest in understanding productivity. For them, productivity is often viewed in terms of the quantities of harmful effluents or important 
resources, such as energy or water, that are produced or consumed. Such "environmental productivity" measures include tons of $\mathrm{CO}_{2}$ (or other air pollutants) emitted per kilowatt-hour $(\mathrm{kWh})$ of electricity produced in a power plant or the emissions per vehicle-mile driven by an automobile.

Typically for the economist, the engineer, or the farmer, improving productivity aims to lower production costs. In turn, these lower costs may lead to lower prices and thereby to increased demand (and thus ultimately further increased production). Most people concerned with the environment today advocate the reduction of environmental impact through increased environmental productivity; previous efforts to promote the alternative-reducing input by scaling back production and consumption (that is, by curtailing material well-being) - have turned out to be generally unpopular. Improved environmental productivity can be achieved through reductions in the use of environmental resources (water, energy, land, and materials) and/or the amount of undesired environmental effluents (emissions) per unit of production.

It is widely acknowledged that productivity growth is a primary element in long-term economic growth and concurrent growth in output and consumption. ${ }^{1}$ Productivity growth, fueled by improved technologies, products, and practices, has enabled an astounding expansion of human activities. Growth has been so expansive that almost all aspects of the industrial metabolism now qualify as global change.

Productivity growth is thus at the heart of the multitude of growth processes that have led to widespread concerns about the long-term sustainability of the human enterprise. These concerns are centered in the domain of resource availability: The question is, how can the benefits that productivity growth has brought to the currently affluent be shared with the majority of the world's citizens? More recent concerns focus on the assimilative capacity of local, regional, and global environments to dissipate waste streams and pollution arising from highly productive (and thus high-output) human systems, because these wastes ultimately threaten the basic life-support functions of the biosphere.

While it seems to be the crux of the problem, productivity growth is also at the heart of a potential solution, a leap of logic that engineer and former MIT president Paul Gray describes as a "paradox of technological development." Technological evolution simultaneously enables increases in output (either directly through new products or indirectly via economic productivity growth), which amplifies humankind's "environmental footprint," while it promotes the reduction of adverse impacts by lessening the resource and environmental intensiveness per unit of output. ${ }^{2}$ Reducing undesirable waste streams, effluents, and pollution can be achieved by reducing output and consumption, which is a daring proposition in view of the need to provide modern services and amenities for all inhabitants of the planet-not just for an affluent minority. Alternatively, environmental improvements can be achieved by maintaining, or possibly expanding outputs while reducing inputs, waste, and pollution. Such "resource productivity," or environmental productivity, is at the core of a debate between technology pessimists and optimists. The pessimists point to the fact that, with few exceptions, improvements in environmental productivity growth have been vastly outpaced by output growth. The optimists high-

(Picture removed because of copyright reasons)

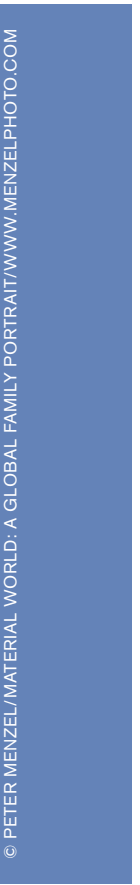

Human life everywhere requires materials, but levels of materials use are not consistent across societies. This family in Mali displays their worldly possessions. 


\section{Productivity growth is at the heart of the multitude of growth processes that have led to widespread concerns about the long-term sustainability of the human enterprise.}

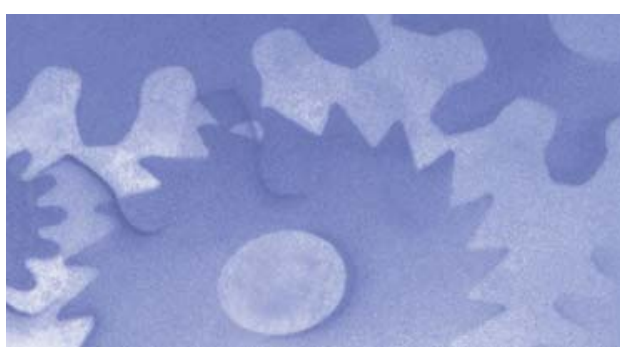

light vast potentials of improved resource and environmental productivity by the application of best practices and technologies as well as the fact that, historically, people have improved resource and environmental productivity even in the absence of environmental concerns and incentives. The task ahead is thus one of accelerating desirable productivity trends well beyond historical experience: a challenging task, but not an entirely new ballgame.
To explore the possibilities, it is important to briefly review examples of historical productivity growth using a variety of metrics. The engineering community has been instrumental in shaping achievements as well as (often unintended) negative environmental consequences. It is therefore illustrative to outline the challenges ahead for green engineers through six "paradoxes" that are likely to shape the definition of green engineering as well as the dichotomies inherent in redesign-

ing the industrial metabolism. On a more cautious note, the technological optimism inherent in engineers needs to be tempered by a recognition of the social and institutional frameworks (and their complexities) in which all engineering is deeply embedded. Societies and institutions frame the conditions under which green engineering can blossom in the future and the terms under which proposed "green" solutions are adopted, counter-caricatured, or sometimes even rejected by society at large.

\section{Examples of Productivity Growth}

Only a truly long-term perspective reveals the astounding extent of productivity growth that has characterized industrial countries since the onset of the Industrial Revolution. Productivity has improved enormously across a multitude of dimensions and indicators. Perhaps the best-known examples are productivity increases in the production of goods and services per unit inputs (particularly labor but also materials and energy). Next to this quantitative dimension of continually producing more per unit of input, there are important qualitative dimensions of productivity growth. Not only do we produce ever more, but we produce an ever larger variety of services and products at ever higher quality. Anyone who has ever driven a Ford Model $\mathrm{T}$ automobile can appreciate the extent of the improvements

More technological advancement necessitates the use of more materials, as demonstrated by this family in Japan. Manmade materials require other resources for their production. 
in product variety and quality that have characterized a seemingly standardized technological object. Next to these quantitative and qualitative dimensions there is an important economic dimension: ever lower real-term (that is, after correcting for inflation) costs and prices, particularly of mass-produced products and services.

Perhaps the most impressive examples can be found in the delivery of services such as telecommunications or illumination. The real-term costs of a 3-minute telephone call from New York to London declined by a factor of about 300 between 1925 and $1995 .{ }^{3}$ Similarly, the productivity growth in the costs of delivering illumination, from tallow candles to modern compact fluorescent light bulbs fueled by electricity, has also improved by more than a factor of 300 over the last 200 years. ${ }^{4}$ Considering that productivity growth has also enabled vastly rising wages, the amount of work-hours required (especially when rising wages enable increased purchasing power) - a positive feedback loop in the language of systems engineering. Such a loop is also at the core of the eternal rat race between the resource-saving aspects of productivity growth and the demand increases that productivity growth enables. Finally, there is also the dimension of environmental productivity, referring to the improvements in the materials and pollution intensity of production and consumption. Again, it is easy to forget how much environmental productivity has increased along many indicators for advanced, industrialized societies. Many environmental problems that plagued industrial societies in the nineteenth century-from horse manure on the streets to the excessively high levels of pollution that went along with coalburning in residential and commercial applications - are no longer known today to the citizens of industrialized countries services of unprecedented quality and variety. ${ }^{6}$ The production side of our consumer society has led to unprecedented levels of material use and environmental impacts as improvements in resource and environmental productivity have been outpaced by output growth to date. The essential fact is that we use resources and make products more efficiently, but we always produce and consume more. As a result, the impacts of human activities are now ubiquitous and have reached planetary-scale proportions, a phenomenon rightly referred to as "global change."

\section{Six Paradoxes}

- Paradox 1: We need green engineers to solve the problems created by the success of engineering. The aforementioned impressive productivity gains and resulting output growth can legitimately be
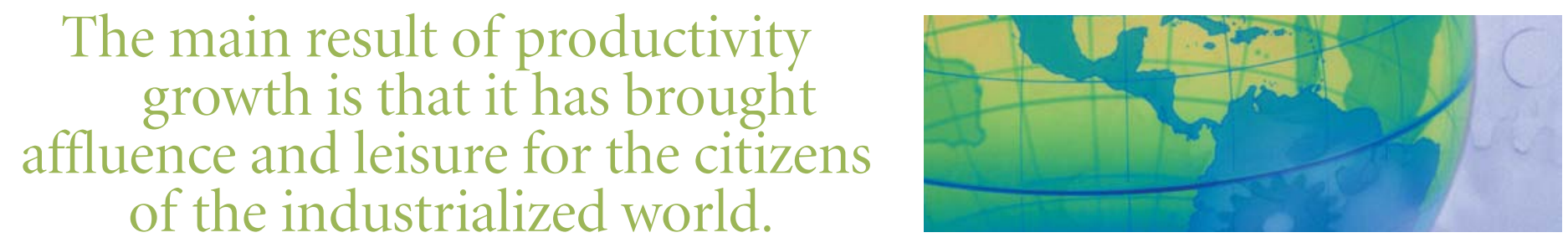

to buy illumination (in lumen-hours) has declined by a phenomenal factor of 45,000 over the last 200 years. Current averages suggest that a person in a developed country needs to work less than one second ( 0.7 seconds to be precise) to be able to afford the light that shines from a 100-watt lightbulb for an hour. Producing the same amount of light in purchasing tallow candles in 1800 required one to toil for nearly 9 hours (roughly 31,000 seconds).

Evidently there are important feedback effects between quantities and prices: As economic productivity increases (as realterm prices decline), demand expands although they continue to be very well known to urban residents in many cities in the developing world.

In a nutshell, the main result of productivity growth is that it has brought affluence and leisure for the citizens of the industrialized world. Over the last 100 years, income has grown on average 3 percent per year, translating into a 20 -fold increase in real incomes. ${ }^{5}$ At the same time, life expectancy has doubled and working time has halved, implying a fourfold increase in free time. Higher incomes and more free time enable us to consume unprecedented quantities of (ever cheaper) products and attributed to the success of the engineering discipline in devising new products and processes and their continual improvements. And yet, when analyzing the human footprint on the planet, the success story of engineering needs to be contrasted with the recognition of the scale of resource utilization and alterations in major biochemical cycles in which humans now rival or even surpass nature.

Humans use approximately 60 percent of the planet's land, one-third of all freshwater resources (both mostly for agriculture), and roughly 100 billion tons of materials annually—about four times the 


\section{The essential fact is that we use resources and make products more efficiently, but we always produce and consume more.}

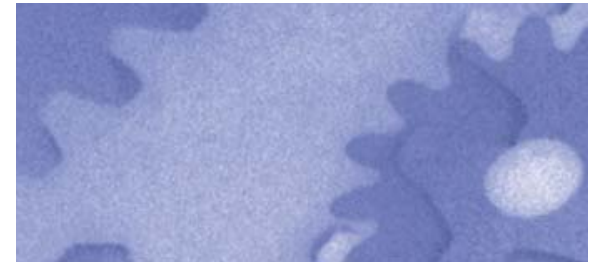

material transported by all rivers on the planet. Effluents from industrial metabolism also exceed natural flows many times over. In addition to major alterations in global biochemical cycles such as those of nitrogen and sulfur, new substances have been introduced, some of them, like chlorofluorocarbons (CFCs) or dichlorodiphenyltrichloroethane (DDT), with unintended and highly negative environmental consequences. The necessity of lightening the human footprint on the planet is evident, and the task itself a challenge, especially when considering future population growth and the aspirations of the poor to catch up to standards of material well-being experienced in the industrialized world. Fulfilling such aspirations, while simultaneously reducing stresses on resource use and impacts from pollution, is the essential challenge of green engineering.

\section{Figure 1. Global metals production and emissions}

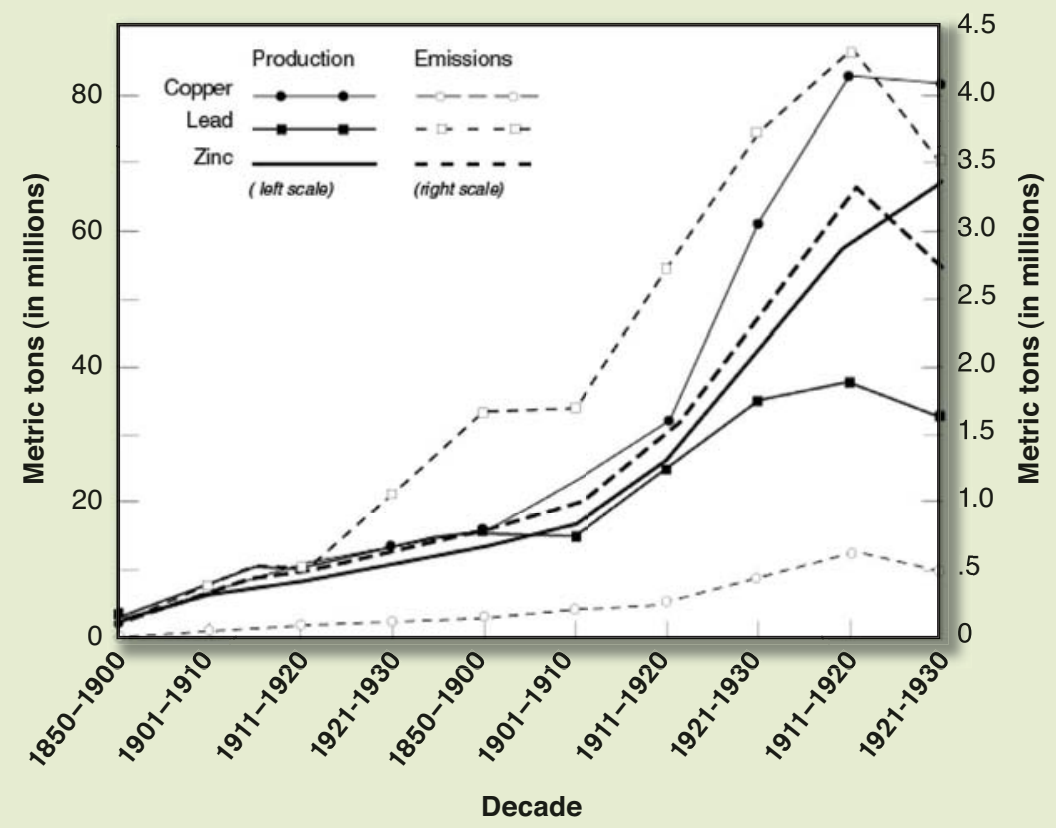

SOURCE: J. O. Nriagu, "A History of Global Metal Pollution," Science, 272, no. 5259 (12 April 1996): 223-4.
As daunting as the task ahead appears, there are also encouraging signs of progress. It is possible to decouple levels of material use from undesirable environmental impacts, even if such decoupling is a recent phenomenon of the industrial enterprise (see Figure 1 on this page). Since the 1970s, for instance, global emissions of heavy metals have progressively decoupled from the production of copper, lead, and zinc as a combined result of changing awareness, environmental regulation, and the changes in industrial engineering practices and processes these have induced. Still more needs to be done, and green engineers need to focus more on seemingly innocuous materials and processes in addition to the ones already identified as potential or actual hazards to the environment.

- Paradox 2: Long after the Stone Age, we used more crushed stone in 30 years than our ancestors used in 30,000. A quantitative view of the world from a materials accounting perspective yields a true giga-perspective. Global material mobilization of biomass, energy, minerals, and other (construction) materials have grown to levels of several billion tons per year (see Table 1 on page 28). Although we tend to associate industrial societies with the use of modern, advanced materials, a quantitative analysis reveals that construction materials and fossil fuels (about 25 billion tons annually) constitute an overwhelming proportion of all materials mined and used.

Consider crushed stones as an example, next to wood, the oldest construc- 
tion material used by humans. Currently, people extract and use about 10 billion tons of stones each year, which is approximately 1,000 times more than what was used roughly 2,000 years ago. (see Figure 2 on page 29). Given the quasi-exponential growth that has historically characterized the expansion of the industrial metabolism (especially over the last 200 years), it is easy to calculate that the current generation has used more crushed stone than all preceding ancestors combined. For instance, more than two-thirds of all estimated stone extraction has taken place since 1975, compared to one-third over the entire time horizon AD 0 to 1975 (see Figure 2). As such, even a material used ever since the Stone Age portrays the same pattern as observed for modern materials such as minerals and fossil fuels: more resources have been consumed since the end of World War II than in all of the human history preceding it. ${ }^{7}$
Even if stones appear environmentally innocuous, sheer scale matters. Extraction of crushed stone, sand, and gravel in densely populated areas (these low-value construction materials tend not to travel far) requires valuable land that is disturbed prior to reclamation and often significantly interferes with ground water.

It is also worth noting that levels of material use continue to be very different across societies, even within the industrialized world. Whereas the much higher energy use of the United States (compared to Europe and Japan) has received widespread attention, it is less known that Europeans on average use about twice as much construction material as similarly affluent Americans. Thus, levels of material use (and environmental implications) do not scale simply with income, indicating an important area for research: discovering the links between affluence, materials use, and social and institutional settings, which characterize persistent dif- ferences within and across different pathdependent "material worlds," and possible scenarios for their future development. ${ }^{8}$ In short, the challenge ahead for industrial ecologists is to better understand demand, as opposed to the customary descriptive approach in industrial ecology or material flow analysis that considers demand largely as a given.

Another illustration of material/environmental intricacies is provided by fossil fuel use. Even if environmentally harmful effluents (such as particulates, sulfur, and nitrogen) are controlled through the application of end-of-pipe engineering solutions, the inevitable oxidation of carbon to $\mathrm{CO}_{2}$ during combustion still yields an alteration of the composition of the atmosphere and thus leads to climate change. An extension of traditional endof-pipe approaches to $\mathrm{CO}_{2}$, for example, through much-discussed concepts of carbon sequestration and storage, faces a huge materials handling challenge. ${ }^{9}$ Glob-

Table 1. Global materials mobilization, year 2000, in billion tons per year

\begin{tabular}{|l|c|c|c|c|c|c|c|}
\hline & $\begin{array}{c}\text { Fossil } \\
\text { energy }\end{array}$ & Metals & $\begin{array}{c}\text { Industrial raw } \\
\text { materials }\end{array}$ & $\begin{array}{c}\text { Construction } \\
\text { materials }\end{array}$ & $\begin{array}{c}\text { Earth } \\
\text { moved }\end{array}$ & $\begin{array}{c}\text { Food } \\
\text { and fibers }\end{array}$ & Total \\
\hline Mining/harvesting & 10 & $>5$ & 2.5 & $\sim 16^{\text {a }}$ & - & $>5$ & $<40$ \\
\hline Overburden, wastes & $>20$ & $>15 ?$ & $<1$ & $>1$ & $>50$ & $<5$ & $<100$ \\
\hline
\end{tabular}

a People extract 10 billion tons of crushed stone for construction. The remainder of the 16 billion tons of construction materials listed consists mostly of sand and other agglomerates.

SOURCE: A. Grubler, "Technology, Global Change and Industrial Ecology," in D. Bourg and S. Erkman, eds., Perspectives on Industrial Ecology (Sheffield, UK: Greenleaf Publishing, 2003), 46-57. 
al carbon emissions from the burning of fossil fuels equal roughly 6 billion tons of elemental carbon (and almost four times that amount in $\mathrm{CO}_{2}$ ) every year, exceeding every other industrial or agricultural commodity in weight and material handling challenges. Thus, in addition to the traditional toxicity concerns that have been at the heart of much of environmental regulation and of green technologies in the past, sheer scale is an important factor. This emphasizes the need to better understand dematerialization trends that have been heralded by some as a potential panacea to environmental problems.

- Paradox 3: Dematerialization occurs at ever-higher levels of materials use. "Dematerialization" is the progressive decrease in required material per unit of output, for example, a reduction in the amount of construction wood necessary to build a square foot of housing. A variety of quantitative measures is possible, depending on which types of materials and which types of output measures are being considered. Frequently, the use of various materials per unit of gross domestic product (GDP) is used in dematerialization studies (see Figure 3 on page 30). Other indicators include, for instance, environmental impacts per unit of material produced or used or the amount of wastes generated per unit of human activity or per person or household.

Whereas dematerialization trends in terms of a decline in the material intensity of economic output are well documented, there is no concluding evidence yet that material use has also decoupled from economic activities in absolute terms. At best, dematerialization has led to a stabilization of absolute material use at high levels. The long-term history of materials use in the United States is among the best researched and thus serves as illustration of the dematerialization paradox. Even taking the most pertinent long-term declining trends of materials use per GDP, it is interesting to note that these dematerialization trends have to date never exceeded three percent per year-equivalent to the long-term rate of economic growth in the United States. This explains that even for timber, absolute demands are similar to levels that prevailed 100 years ago, despite a secular trend toward relative dematerialization.

Given the historical record that points to a stabilization of materials use in indus- trialized countries at high levels and a substantial potential of future growth arising from economic "catch-up" of those who are currently poor, green engineers need to focus on furthering and accelerating advancements in materials use in the industrialized as well as the developing world.

- Paradox 4: Engineers to date have never won the rat race between productivity and output growth, but farmers did. A simple accounting identity has

\section{Figure 2. Global stone extraction and percent of cumulative extraction}

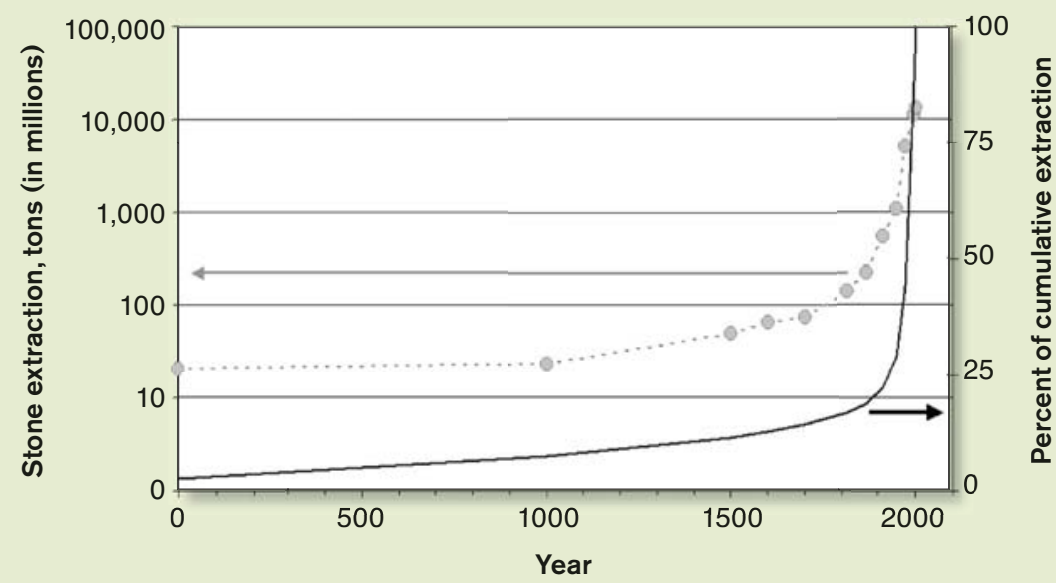

NOTE: The data represent zero order estimates based on the available few published current global and historical U.S. stone extraction figures that have been correlated with Angus Maddison's long-run population and economic growth estimates.

Source: P. W. Harben and R. L. Bates, Industrial Minerals: Geology and World Deposits (London: Metal Bulletin Plc, 1990); A. H. Reed, "Stone," in U.S. Bureau of Mines, Minerals Yearbook 1975 Vol I (Washington, DC: U.S. Bureau of Mines, 1975): 1311-88; T. Kelley et al., Historical Statistics for Mineral and Material Commodities in the United States, U.S. Geological Survey Open-File Report 01-006 (http://minerals.usgs .gov/minerals/pubs/of01-006/); and A. Maddison, The World Economy: A Millennial Perspective (Paris: Organisation for Economic Co-operation and Development (OECD), 2001). 
frequently been referred to as the "master equation" of industrial ecology. ${ }^{10}$ In this I=PAT identity, environmental impacts (I) are seen as the product of population $(\mathrm{P})$ times levels of affluence (A) times levels of technology applied (T). The convenience of I=PAT primarily arises from the fact that it enables simple decompositional analysis because the derivative component growth rates are additive $(\mathrm{I}=\mathrm{P}+\mathrm{A}+\mathrm{T})$. When using the I=PAT identity, there are some important caveats: One must not use the I=PAT identity over too large of a sample area, nor should one

\section{Figure 3. U.S. materials intensity per GDP and absolute materials use}
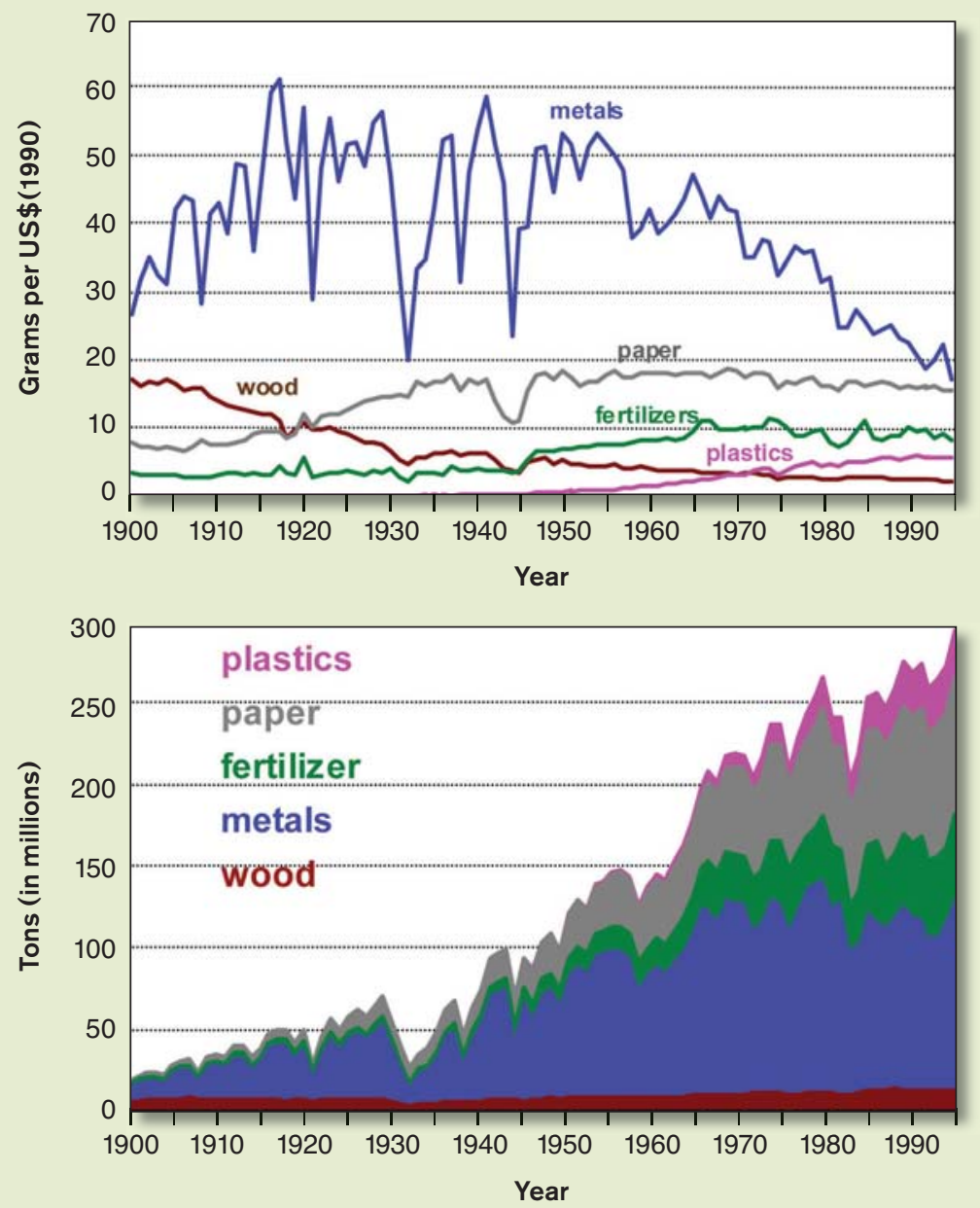

SOURCE: I. K. Wernick and J. H. Ausubel, "National Materials Flows and the Environment," in Annual Review of Energy and the Environment 20 (1995): 462-92. ignore variable interdependence. ${ }^{11}$ For instance, the growth in energy-related carbon (dioxide) emissions in the United States can be illustrated by writing the following multiplicative identity: ${ }^{12}$

Carbon $=$

GDP x Energy/GDP x Carbon/Energy

In terms of (average annual) growth rates, the following are typical values since the mid-19th century (in percent per year):

$$
1.7=3+(-1)+(-0.3)
$$

In other words, the productivity of energy use has improved in the United States in two ways. Energy use per unit of GDP improved with a rate of about one percent per year (dematerialization), and carbon emissions per unit of energy (a trend frequently referred to as decarbonization) improved at a slow 0.3 percent per year. It is more important to recognize that these material and environmental productivity improvements (1.3 percent per year), have been dwarfed by the growth in economic output (growing at roughly 3 percent per year). The difference (1.7 percent per year) reflects the growth of environmental impacts (such as possible climate change due to accumulation of $\mathrm{CO}_{2}$ emissions in this example). In short, these trends indicate that, to date, engineers have never won the rat race between material/environmental productivity growth on one side and output growth on the other.

But perhaps engineers can learn from farmers, who have, at least in industrialized countries, won the race between productivity and output growth, managing to progressively decouple the expansion of arable land use from a growing population (see Figure 4 on page 32). Particularly since 1950, increases in agricultural productivity have led to progressively fewer land-conversions for a growing popu- 
lation. The effects have been dramatic and widespread. Productivity increases in Europe and North America allowed, for the first time since the Industrial Revolution, agricultural lands to be reconverted to forests (see the negative values of land-conversions per additional population in Figure 4) while maintaining tremendous increases in agricultural output (and surpluses).

Approximately 18 million hectares that were previously plowed have been returned to a state of nature in Europe and North America since 1950. This indicates absolute resource shortages for farmland, minerals, or energy. With a finite Earth, such concerns are certainly warranted in the (very) long term. However, analysts are less certain what "long term" means in terms of resource availability: a few decades (as pessimists have been arguing repeatedly) or perhaps a time scale of centuries, even millennia. This debate about resource availability fluctuating between the extremes of penury or abundance has been particularly pronounced in the energy field, which is why the limits to growth paradox is illustrated here using economic and technological feasibility. "Reserves" (the most frequently cited numbers of imminent resource scarcity) are the most straightforward quantity (but also the most misleading one). "Reserves" only include deposits that have been identified and that can be mined given current prices and technology. As a result, the term "reserves" is far from being a geological concept (quantities available) but is primarily an economic one (recoverable quantities at given prices). Energy reserves mostly include deposits of conventional materials that have been easy to

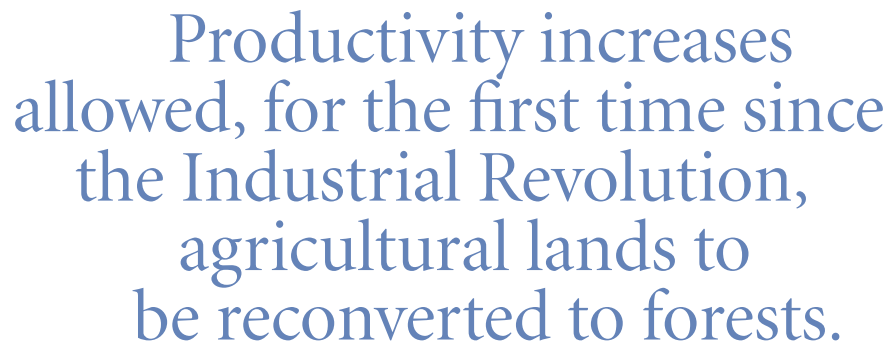

that the balance between output and productivity growth can finally also tilt in favor of absolute resource conservation. Even in this positive example, however, one needs to be cognizant of the fact that one cannot win on all productivity fronts at the same time. Raising agricultural yields spared land and allowed even more land to be reconverted to forests, but at the same time it required increasing intensification of production on the remaining agricultural fields and hence more fertilizer, water, and (fossil) energy use. The quest for ever-higher productivity needs to go on while considering a multitude of dimensions and indicators.

- Paradox 5: Limits to growth: Not the most that we are able to take away from nature; rather, the most that we are able to return to it as wastes. One of the main motivations for resource conservation has always been the fear of running out: facing fossil fuel resources as an example. The traditional "supply" concerns need to be complemented with an even stronger concern on the "disposition" side of the resource availability equation.

When discussing energy resource availability, it is useful to recognize that available resources need to be defined along a multidimensional space comprising (geological) knowledge, economics, and technology. In other words, what constitutes a "resource" depends on whether particular deposits have been found and whether the deposits can be extracted economically (at prevailing prices) as well as technologically (with current technology). Because all three dimensions that define resource availability are inherently dynamic, it is necessary to refrain from simple numbers, focusing instead on a continuum of quantities with varying degrees of geological assurance and

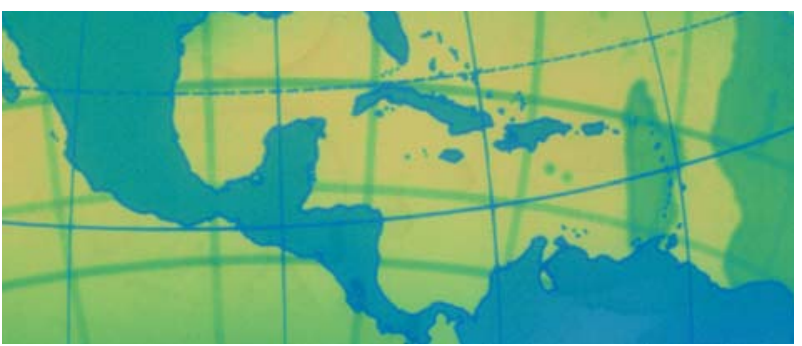

find and are easy to produce but increasingly (with technological improvements) also include so-called "unconventional" resources such as tar sands in Canada, heavy crudes in Venezuela, or methane extracted not from gas fields but from coal seams. For instance, Germany and Poland already produce natural gas from coal seams commercially, tapping into their "unconventional" reserves.

The next category is usually referred to as "resources" and includes conventional as well as unconventional deposits that are either less well known or cannot be produced with current prices or technology (or both). Assuming improvements in economics and technology, some (or even a large part of) resources may in the future turn out to become "reserves" as they have done in the past; this explains how the quantities of "reserves" have continuously grown over time despite ever larger 
production volumes. But the timing and extent of these additions to our reserve base remain uncertain. Finally, there is a last category, referred to as "occurrences." Typically these are either exotic deposits (like methane hydrates) or conventional resources that appear beyond reach within the foreseeable future (like the coal seams buried under the North Sea). It is interesting to note here that contrary to conventional wisdom, the largest occurrence of hydrocarbons in the Earth's crust is not in the form of coal but in the form of methane hydrates: molecules of natural gas (methane) trapped in the lattice of frozen water molecules. Hydrates are estimated to exist in enormous quantities in permafrost areas and in the ocean floor of continental shelves.
Table 2 on page 33 summarizes current estimates of reserves, resources, and occurrences for coal, oil, and natural gas. Instead of the traditional energy units, carbon is the measurement metric, so all quantities are expressed in gigatons of carbon ( $\mathrm{GtC}$, billion tons of elemental carbon). Historically, extraction and burning of fossil fuels have amounted to approximately $290 \mathrm{GtC}$ over the period 1800-2000. This figure compares with an additional $160 \mathrm{GtC}$ released by land-use changes (deforestation): that is, a total release of about $450 \mathrm{GtC}$ since the onset of the Industrial Revolution. According to the Intergovernmental Panel on Climate Change (IPCC), this release constitutes an already "discernable influence on the climate system," as it has raised atmospheric

\section{Figure 4. Changes in agricultural land use (1700-1980)}

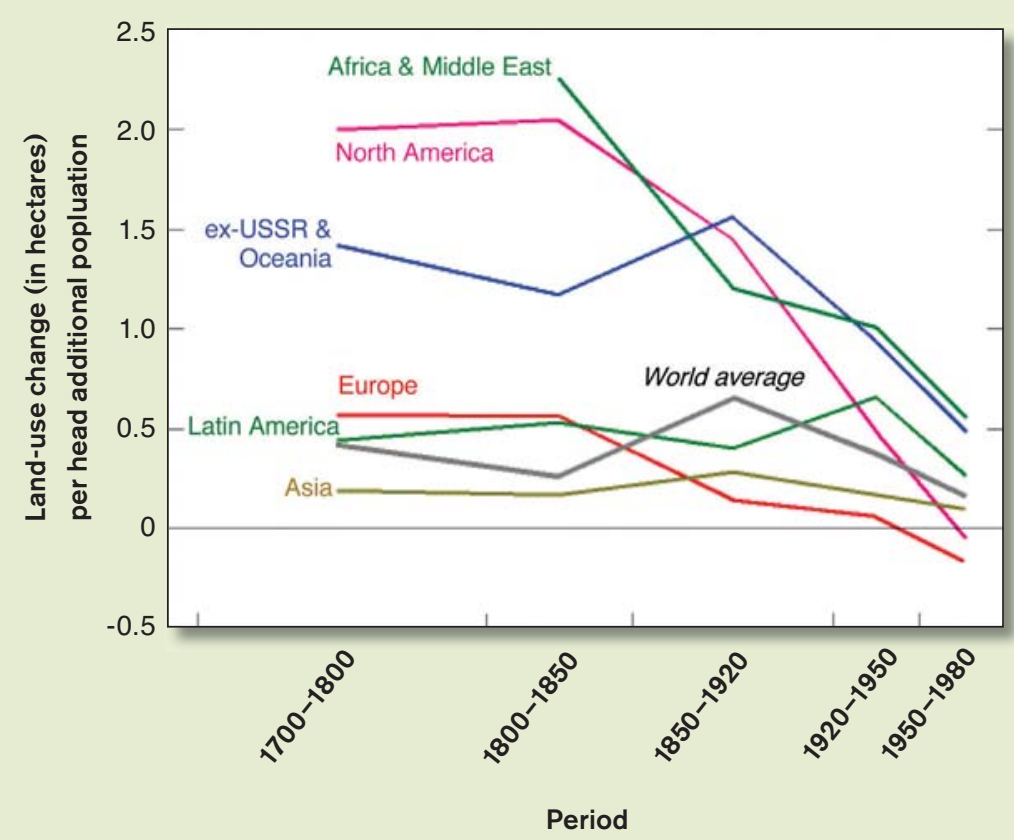

SOURCE: A. Grubler, Technology and Global Change (Cambridge, UK: Cambridge University Press, 1998). concentrations of $\mathrm{CO}_{2}$ from 280 parts-permillion by volume (ppmv) in pre-industrial times to about 370 ppmv today. ${ }^{13}$ The latter figure corresponds to approximately 760 $\mathrm{GtC}$ contained in the present atmosphere. It is evident from Table 2 that even considering only energy reserves (860 GtC), release of such quantities via the burning of fossil fuels will lead to a continued, amplified human influence on the climate system. Considering potential releases by tapping even a fraction of the estimated available resources (or even occurrences that, combined, contain up to $20,000 \mathrm{GtC}$ ) illustrates the paradox mentioned above. Well before physical resource limitations eventually halt the continued expansion of fossil fuel use, limits of the assimilative capacity of the biosphere will be reached. The ultimate limits to growth are therefore less what humans can extract from nature as resources but rather how much they can return to it as wastes.

- Paradox 6: Consumers can beat green engineers. The last paradox addressed here defines the relationship between the green engineer and that of the (sometimes not-so-green) consumer. It is a truism that despite the nomenclature, all industrialized countries are predominantly service economies. Therefore, from an environmental perspective, it is the consumer end-how products are used and services are delivered (as opposed to the traditional engineering focus on how they are manufactured)-that matters increasingly more. For engineers this means that increasing attention needs to be paid to potential new fields of technology application and to consumer behaviors that can either promote environmental improvements or exacerbate problems. An illuminating example of this is provided by trends in U.S. automobiles and their carbon emissions since 1970 following a decompositional I=PAT analysis (see Figure 5 on page 34$).{ }^{14}$ 
remaining the same, automotive emissions should have fallen in proportion to the mandatory emissions standards for cars. However, this has not been the case, as the U.S. Environmental Protection Agency (EPA) emissions statistics clearly indicate. ${ }^{16}$ The tightening of emissions standards for hydrocarbons and CO by 90 percent compares with emissions reductions of 30-50 percent for $\mathrm{CO}$ and volatile organic compounds (VOCs), respectively. There has been no emissions reduction for $\mathrm{NO}_{x}$ compared to 1970, despite tightening emissions standards to 25 percent of 1970 levels. The case of $\mathrm{NO}_{\mathrm{x}}$ is a reminder that it is a long and winding road between the introduction of environmental standards and pollution control equipment (catalytic converters in this case) and effective emissions reductions. Counterbalancing factors include the changes in vehicle usage mentioned above leading to continued demand growth (more cars and more driving per passenger transported), and changes in vehicle fleet composition (more light trucks and SUVs). But above all, the major offsetting factors are the differences between actual emissions in everyday operations and emissions under test conditions as demanded in regulatory standards. For instance, it is estimated that there is a factor difference of $2\left(\mathrm{NO}_{\mathrm{x}}\right), 4$ (hydrocarbons), and $5(\mathrm{CO})$, respectively between the actual average emissions over a vehicle's lifetime and those postulated by the 1993 tailpipe automobile emissions standard in the United States due to short-distance driving or bad maintenance,

\section{Figure 5. Trends in carbon emlssions from U.S. automobiles and related factors}

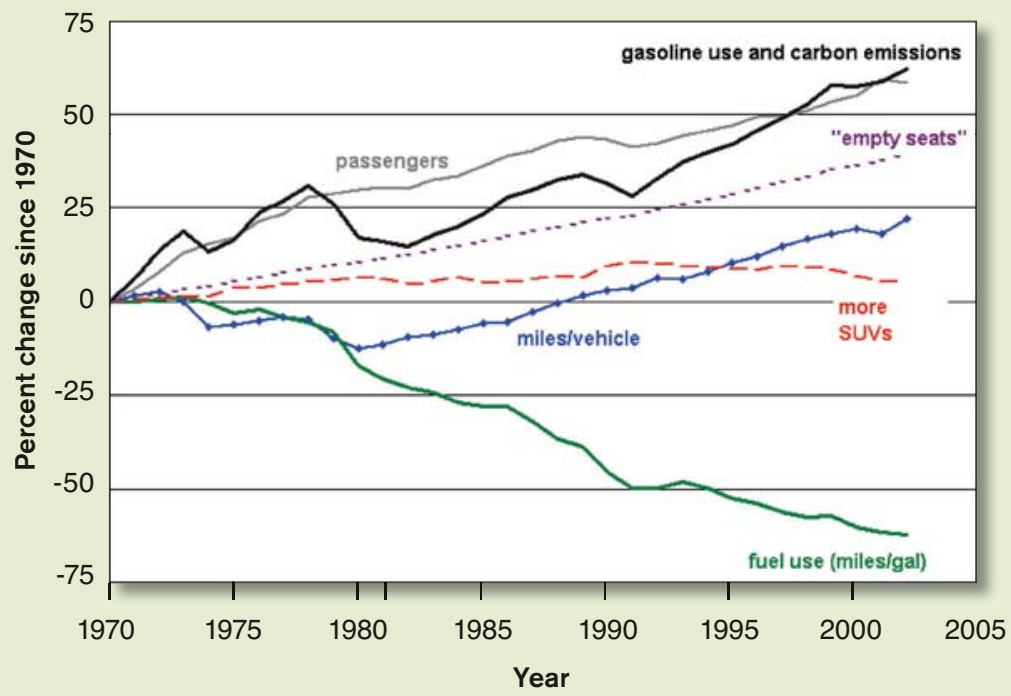

SOURCE: Based on data from S. C. Davis et al., Transportation Energy Data Book: Edition 24 (Oak Ridge, TN: Oak Ridge National Laboratory, 2004), http://cta.ornl.gov/data/index.shtml (accessed 17 January 2006).

all leading to malfunctioning of catalytic converters. ${ }^{17}$ In combination with continued demand growth, these factors explain the apparent difference between actual emissions levels and those expected based on the diffusion of vehicles with new and improved environmental standards.

These results caution against over-optimism regarding the pace and effectiveness of pollution reduction measures based on "add-on" devices, where their environmental performance is largely determined by consumer usage and maintenance and where service demands continue to grow. It also suggests that mandatory emissions standards have to leave large margins for these counterbalancing effects. From that perspective, the best standard is one of zero emissions, and, indeed, with the introduction of lead-free gasoline, lead emissions from automobiles have been reduced to practically zero in the United States. ${ }^{18}$ However, there is yet another interpretation: Instead of confirming the cliché that the problem in emissions control is not technical but rather institutional or behavioral, the divergence between regulatory standards and actual emissions can also be seen as resulting from a lack of accurate emissions measurement instrumentation. This consequently leaves regulators and car manufacturers groping in the dark-without adequate information on which to base standards and research and development (R\&D) in emissions control technologies. So in rephrasing the above paradox, one can conclude that consumers can easily beat green engineers, particularly if the engineers start from a position of poorly engineered environmental standards and progress monitors.

\section{Conclusions}

A set of six paradoxes provides a framework for the challenges that green engineers face in today's industrial 
metabolism. Vastly improved productivity leading to new, better, and cheaper products and services is at the heart of the tremendous output growth that has led to current concerns of environmental sustainability. Improved materials and increased environmental productivity have substantially lessened the environmental impacts of output growth, even if, to date, output growth has generally outstripped improvements. But the fact that these improvements have taken place for extended periods of time even in the absence of environmental concerns and regulation gives reasons for cautious optimism: Given appropriate incentives from within the engineering community and from society at large, historical material and environmental productivity improve- not necessarily always move in consistent directions. A larger systems perspective is also needed in terms of the geographical focus on existing markets (predominantly in industrialized countries) toward a more global view, including transfer and diffusion of best practice engineering and engineering solutions to developing nations. From these perspectives, green engineering is indeed a new, holistic discipline with its concerns on redesigning entire systems of production and use, embracing process and product design changes as well as embracing a global perspective.

Perhaps the most important lesson from large systems boundaries is for engineers to recognize the importance of consumer behavior and the end-of-life of engineering products and solutions. But here, the of the paradoxes outlined in this essay. Green engineering "fixes" are unlikely to move systems of production and use beyond good practice, despite the substantial margins of improvement that the global application of best engineering practices may entail. To minimize environmental impacts by significant orders of magnitude requires the blending of good engineering with good economics as well as changing consumer preferences. If improved environmental productivity entails increased costs, these costs need to be either balanced by appropriate market incentives, either through sticks (for example, adding environmental externalities to the cost calculus) or through carrots (for example, changing consumer preferences that give green products a

\section{Perhaps the most important lesson from large systems boundaries is for engineers to recognize the importance of consumer behavior and the end-of-life of engineering products and solutions.}

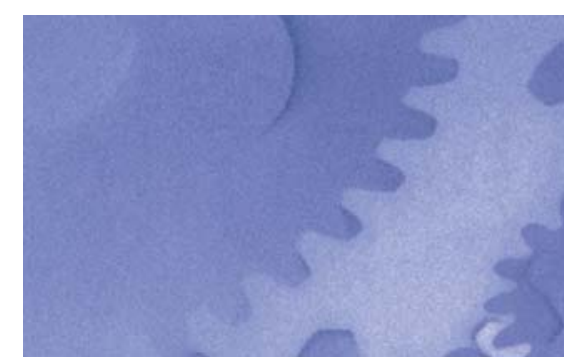

ments could be substantially accelerated, ultimately outpacing output growth and in turn leading to less resource use and environmental stress.

The six green engineering paradoxes explored here highlight the importance of large system boundaries and the use of multiple criteria for design and implementation of green engineering solutions. Embracing a larger systems view not only should help green engineers enhance traditional "good" engineering practice but also help in addressing inevitable tradeoffs inherent in balancing environmental and economic performance criteria as well as possible tradeoffs between various environmental objectives that may green engineer who has learned successfully from the natural (environmental) sciences faces a new challenge: to learn from and interact with the social sciences. The technological optimism (if not determinism) inherent in engineers needs to be tempered with a recognition of the complexities of social and institutional frameworks in which all engineering is deeply embedded. They frame the conditions under which green engineering can blossom in the future as well as the terms under which proposed "green" solutions are adopted, counter-caricatured, or sometimes even rejected by society at large.

This larger systems perspective also holds clues for the ultimate resolution competitive economic edge)—or preferably, both sticks and carrots.

If as a first step we wanted to stabilize resource use and environmental impacts, despite continued demand growth, quantitative performance targets (such as fuel use in automobiles) need to be established via clear policy signals and with sufficient lead-time to allow the development of corresponding engineering solutions. Market incentives in support of these engineering targets could include gradually rising environmental levies and fees at a rate that is commensurate with the desired performance target (for example, 3 percent per year). Revenues could be used to better inform consumers about the 


\section{Well-established studies that describe how technologies improve and become cheaper the more they are tried offer the promise that in the long term, "cleaner and greener" may no longer mean "more expensive."}

environmental externalities associated with particular consumption choices. In addition, the money could assist (through subsidies) those consumers willing to adopt (initially more expensive) cleaner products and services. These revenues could also help to fund the R\&D investments needed to develop green technologies.

Well-established studies that describe how technologies improve and become cheaper the more they are tried offer the promise that in the long term, "cleaner and greener" may no longer mean "more expensive." 19 If, indeed, industrial economies of scale and other engineering cost reduction mechanisms can be harnessed with increasing market deployment rates of cleaner technologies, products, and services, the required market intervention could be made a transitory rather

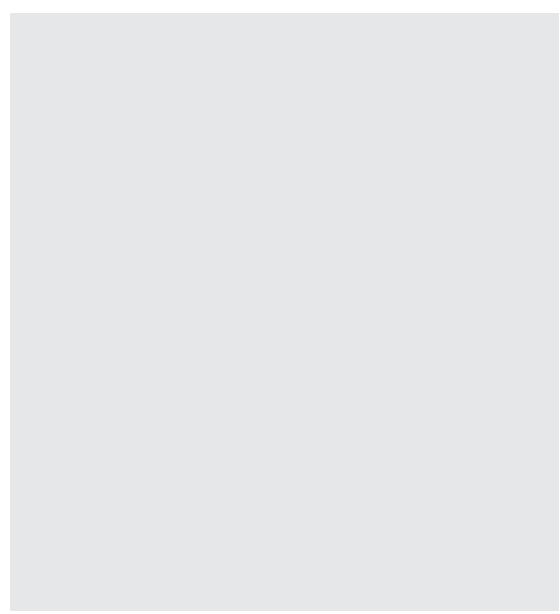

than permanent phenomenon. Continued observation and benchmarking of progress vis-à-vis the evolving opposing trends in consumption growth and environmental productivity improvements can help to continually adjust strategies and incentives, as done successfully in a number of engineering enterprises to coordinate $R \& D$ and market introduction of successive technological generations-each with drastically improved performance. ${ }^{20}$

International cooperation is necessary to harness the widest human creativity potential possible. Such cooperation is also integral in stimulating technology spillover and adoption, particularly in those developing countries where demand growth is vigorous. Finally, a dialogue needs to be opened with social sciences and the arts, changing the way that these disciplines communicate with consumers about the relationship between environmental issues and everyday consumption choices. New concepts beyond traditional scare tactics or denial strategies are sorely needed, as are more playful and optimistic characterizations of improved environmental performances. What is needed, in short, are ideas that depart from traditional normative, negative-tone appeals to consumers' social and environmental responsibilities. Perhaps teams of sociologists and representatives from industrial marketing departments, environmental foundations, and nongovernmental orga-

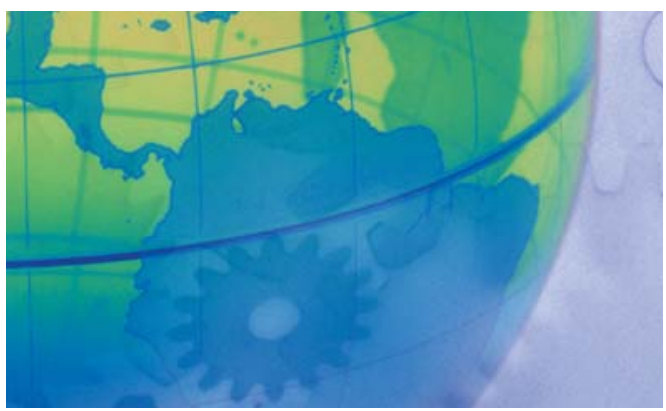

nizations need to be put to the task of crafting the social and economic incentives for greening our engineering.

Arnulf Grubler is a senior research scholar in the Transitions to New Technologies Program at the International Institute for Applied Systems Analysis in Laxenberg, Austria. He also holds a part-time appointment as professor of energy and technology at the Yale School of Forestry. He wishes to thank all participants of the conference, "Green Engineering: Defining the Principles." Their ideas are now also available in print: M.A. Abraham ed., Sustainability Science and Engineering: Defining Principles (Amsterdam: Elsevier, 2006).

\section{NOTES}

1. For examples, see R. M. Solow, Growth Theory and After (Nobel Prize Lecture, 1987), http://nobelprize.org/economics/laureates/1987/solow-lecture.html; E. Denison, Trends in American Economic Growth, 1929-1982, (Washington DC: Brookings Institution, 1985); and N. Rosenberg and L. E. Birdzell, "Science, Technology and the Western Miracle," Scientific American 263, no. 5 (1990): 18-25.

2. P. Gray, "The Paradox of Technological Development," in J. H. Ausubel and H. E. Sladovich, eds., Technology and Environment (Washington DC: National Academies Press, 1989), 192-204.

3. N. Nakićenović et al., Special Report on Emissions Scenarios (Cambridge, UK: Intergovernmental Panel on Climate Change and Cambridge University Press, 2000).

4. W. D. Nordhaus, Do Real-Output and Real-Wage Measures Capture Reality? The History of Lighting Suggests Not (New Haven, CT: Cowles Foundation Paper No. 957, 1998).

5. S. Lebergott, Pursuing Happiness: American Consumers in the Twentieth Century (Princeton, NJ: Princeton University Press, 1993).

6. J. H. Ausubel and A. Grubler, "Working Less and Living Longer: Long-term Trends in Working Time and Time Budgets," Technological Forecasting and Social Change 50, no. 3 (1995): 195-213.

7. R. Noetstaller, "Patterns of Mineral Demand and 
Supply—Global and Regional Perspectives," Berg- und Hüttenmännische Monatshefte (Mountain- and Metallurgical Monthly) 147 no. 12, (2002): 402; and F.-W Wellmer and M. Wagner, "Rohstofftrends am Beginn des 3. Jahrtausends" (Raw Material Trends at the Beginning of the Third Millennium), Erzmetall (Ore Metal) 53 (2000): 569

8. W. B. Arthur, Increasing Returns and Path Dependence in the Economy (Ann Arbor: University of Michigan Press, 1994)

9. H. J. Herzog, "What Future for Carbon Capture and Sequestration?" Environmental Science \& Technology 35, no. 7 (2001): 148A-53A

10. I. K. Wernick, "Consuming Materials: The American Way," Technological Forecasting and Social Change 53, no. 1 (1996): 111-122.

11. A. Grubler, "Transitions in Energy Use," Encyclopedia of Energy Vol. 6 (2004): 163-77.

12. To show the analogy between this expression and I=PAT, the term (GDP) can be broken down into population $\mathrm{x}$ income per head/population. For more information on the I=PAT identity, please see P. R. Ehrlich and J. P. Holdren, review of The Closing Circle, by Barry Commoner, Environment 14, no. 3 (April 1972): 23-4, 36-9.

13. Intergovernmental Panel on Climate Change
(IPCC), Climate Change 2001 (Cambridge, UK: Cambridge University Press, 2001).

14. Carbon emissions from automobiles are proportional to gasoline use. Hence we use this as a metric for our decompositional analysis where gasoline use is the product of:

passengers $\mathrm{x}$ vehicles/passengers $\mathrm{x}$ miles driven/ vehicle $\mathrm{x}$ gasoline use/mile $\mathrm{x}$ SUV adjustment factor

The vehicles/passenger variable is the inverse of the automobile load factor that has decreased from approximately 2 passengers per vehicle in the late 1960 s to 1.6 in 1995. More recent data are trend extrapolations. The SUV adjustment factor accounts for structural changes in the U.S. automobile fleet toward more SUVs and pick-up trucks. Their effect is smaller than the difference in fuel consumption would suggest, because their shorter driving distances, as compared to traditional passenger cars, moderate their characteristically poor gas mileage rating. For this multiplicative identity, component growth rates are additive and thus help to explain their relative contribution to total gasoline use and emissions growth as shown in Figure 5. It is necessary to assume that components are independent from each other, which is a statistical assumption justified only for the purposes of our simplified analysis. In reality, important variable interdependencies exist. For instance, more fuel-effi- cient cars reduce operating costs and also allow driving over longer distances: an effect frequently referred to as consumer "take-back." For more information on the performance of SUVs, see S. Plotkin, "Is Bigger Better? Moving Toward a Dispassionate View of SUVs," Environment 46, no. 9 (November 2004): 8-31.

15. American Automobile Manufacturers Association (AAMA), Motor Vehicle Facts and Figures, (Detroit, MI: AAMA 1996); U.S. Environmental Protection Agency (EPA), National Air Pollutant Emission Trends 1900-1994, EPA-454/R-95-11 (Washington DC, 1995); M. Ross, R. Goodwin, R. Watkins, M. Q. Wang, and T. Wenzel, Real-World Emissions from Model Year 1993, 2000, and 2010 Passenger Cars, Lawrence Berkeley Laboratory LBL-37977 (Berkeley, CA, 1995).

16. EPA, ibid.

17. M. Ross, R. Goodwin, R. Watkins, M. Q. Wang, and $\mathrm{T}$. Wenzel, note 15 above.

18. EPA, note 15 above.

19. For a review, see L. Argote and D. Epple, "Learning Curves in Manufacturing," Science, 23 January 1990, 920-4.

20. A successful example can be found at the International Technology Roadmap for Semiconductors, http:// public.itrs.net/. 



\section{Additional copies}

Further copies of this IIASA Reprint are available online at www.iiasa.ac.at/Publications

Hard copies are also available for a small handling charge. Orders must include the publication number and should be sent to the Publications Department, International Institute for Applied Systems Analysis, A-2361 Laxenburg, Austria.

Telephone: +432236807

Telefax: +432236 71313

E-mail: publications@iiasa.ac.at 
International Institute for Applied Systems Analysis

Schlossplatz 1, A-2361 Laxenburg, Austria

Tel: +432236807 Fax: +43223671313

I I AS A www.iiasa.ac.at 